\title{
Female-Oriented Male-Male Erotica: Comparison of the Engaged Anglophone Demographic and That of the Greater China Area
}

\author{
Anna Madill ${ }^{1}$. Yao Zhao ${ }^{1}$
}

Accepted: 16 September 2020 / Published online: 6 October 2020

(c) The Author(s) 2020

\begin{abstract}
Our aim is to compare comprehensive data on the engaged demographics of femaleoriented male-male erotica in Anglophone regions and that of the greater China area. Our study constitutes the largest such data set in each region (Anglophone $N$ = 1707; Chinese $N=1498$ ). Data were analysed from our online Boys' Love (BL) fandom survey: one version in English and an almost identical version in Chinese. We confirm that the engaged Anglophone demographic includes more men, people with a wider range of sexual orientations, lower proportion of heterosexual identification, and a wider and older age range. We provide greater detail than ever before and demonstrate engagement with BL by young straight men and questioning of sexual identity by female fans, at least in the Anglophone West. Finally, we provide novel evidence that a broad demographic of young people in the greater China area is familiar with BL as a casual interest in contrast to Anglophone regions where it is more of an intense and niche pass-time. We offer important insights into a global erotic entertainment by-and-for women which is influencing the mainstream but under increasing legislative scrutiny.
\end{abstract}

Keywords Boys' Love $\cdot$ Yaoi $\cdot$ Danmei $\cdot$ Pornography $\cdot$ Homosexuality $\cdot$ Femaleoriented erotica

Electronic supplementary material The online version of this article (https://doi.org/10.1007/s1211 9-020-09783-9) contains supplementary material, which is available to authorized users.

Anna Madill

a.1.madill@1eeds.ac.uk

1 School of Psychology, University of Leeds, LS2 9JT Leeds, UK 


\section{Introduction}

Female-oriented male-male erotica is one of the largest by-and-for women sexual subcultures and a truly global phenomenon (Levi et al. 2014). While the content focuses always on men in romantic and/or sexual relationships, the form varies and includes artwork, manga, novels, online instalments, live action serials, and film. Material is created by both amateurs and professionals, and is provided free and as a commercial enterprise. Female-oriented male-male erotica offers online and offline space (e.g., forums and conventions) in which fans can participate and co-create. Designations are many and include shonen-ai and yaoi (Japanese), slash (Anglophone), and danmei (Chinese). Here we use the umbrella term Boys' Love (BL).

BL is important to study. First, as a largely by-and-for women erotic subculture it is of social significance given that women's engagement with pornography is often problematized yet increasingly normative (Attwood et al. 2019). Moreover, as a global phenomenon, BL provides a window into the development of a grassroots sexualised entertainment for women and how this is shaped within different cultural contexts. Here we compare the engaged demographics in the Anglophone West with that of the greater China area (i.e., Mainland China, Taiwan, Hong Kong, and Macau). These are both regions of world significance with contrasting political and social environments (Zhao and Madill 2018).

Second, the popularity of BL is impacting mainstream entertainment. For example, sexually-inflected male relationships are played-up in popular Anglophone TV series such as Sherlock and capitalised on in their marketing (Porter 2012). Moreover, in China, where there is a blanket ban on sexually-explicit material and strong disincentive to acknowledge same-sex relationships in public media (Zhao 2016), eroticism between men is flourishing in mainstream entertainment. For example, in 2018-2019 the online live action series Guardian, adapted from a popular danmei novel, reached 25 billion plays.

Third, BL focused on 'youths' may contravene the law in some jurisdictions. Providing an evidence-based profile of the engaged demographics will facilitate realistic assessment of the risks posed, particularly given increasing regulation of such material. For example, some regulations arguably conflate the production and consumption of non-realistic, sexually-explicit, fictional materials with that of real child pornography (Madill 2015). Currently this is done so without evidence of its harm or interest in its possible positive function for relatively sexually-benign demographics, such as educated young women.

Table 1 presents a summary of the existing research on BL to May 2019 that provides information on the engaged demographics in our regions of interest. Studies on the greater China area BL fandom were searched for on the main Chinese academic databases CQVIP (Chongqing VIP Information), Wanfang, and CNKI (China National Knowledge Infrastructure). Studies on the Western BL fandom were searched for on GOOGLE SCHOLAR because articles cross many academic disciplines. The literature search involved also checking the reference section of relevant articles for further papers. 


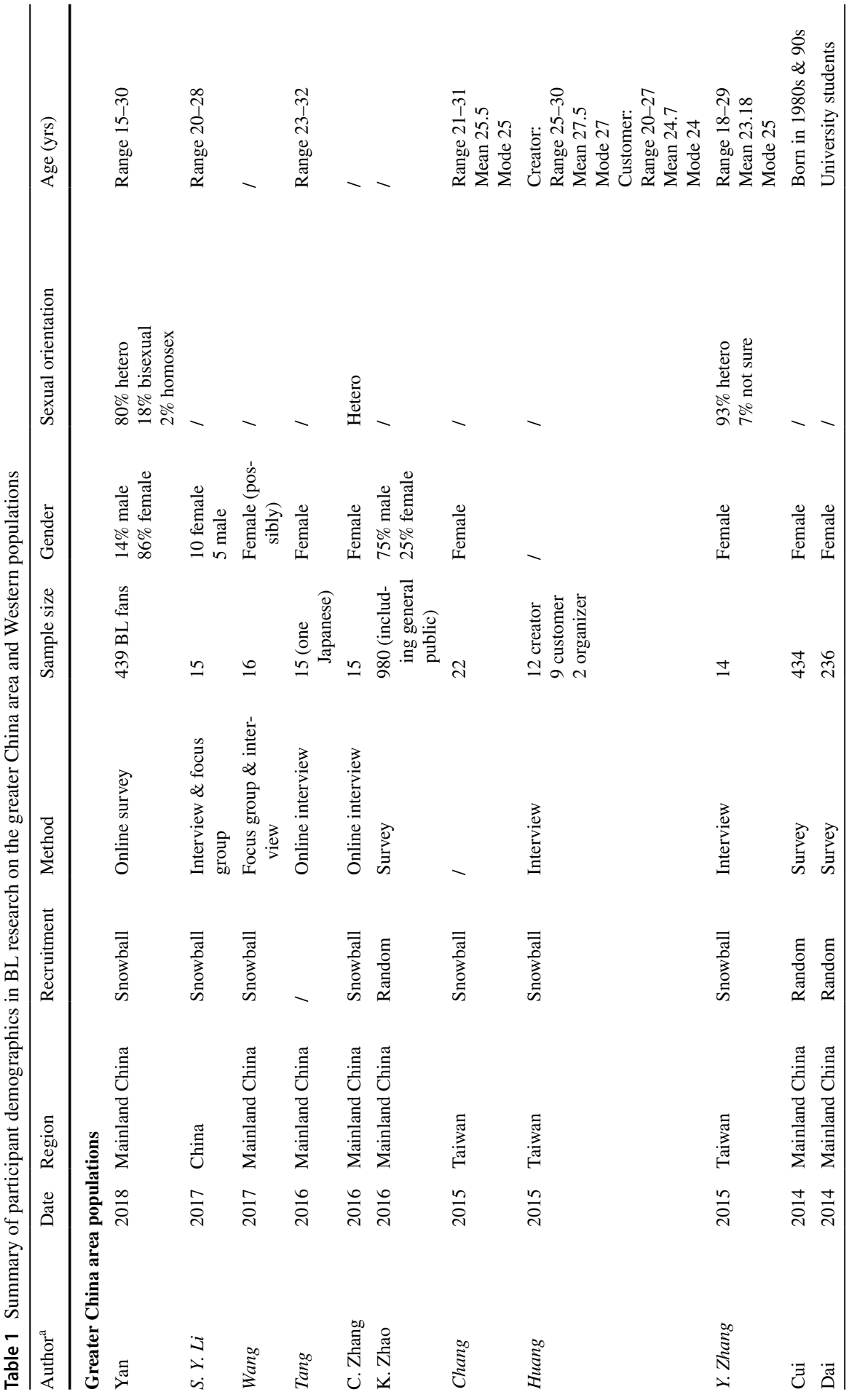




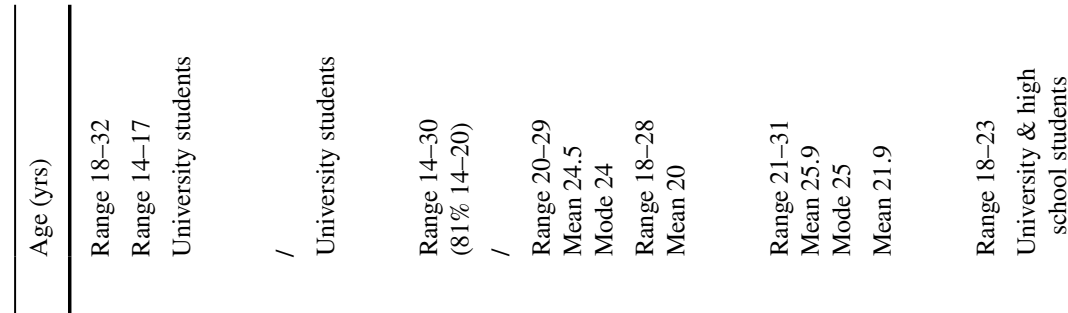

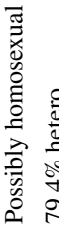

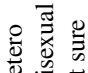

$\underset{0}{0}$

io

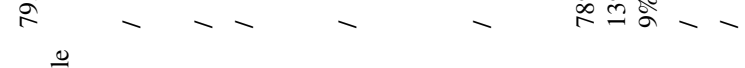

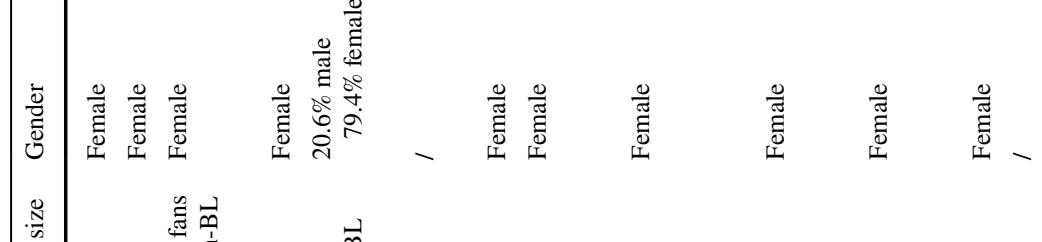

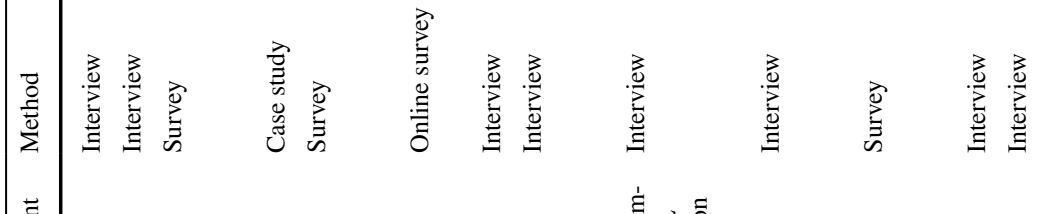

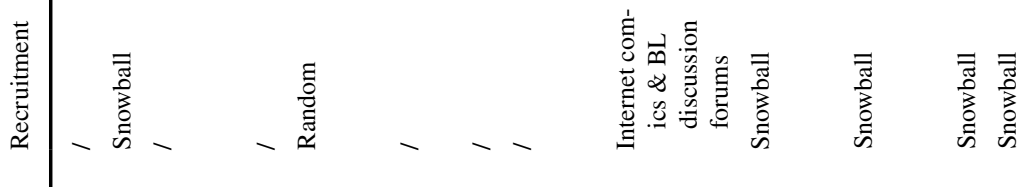

n 0 究离

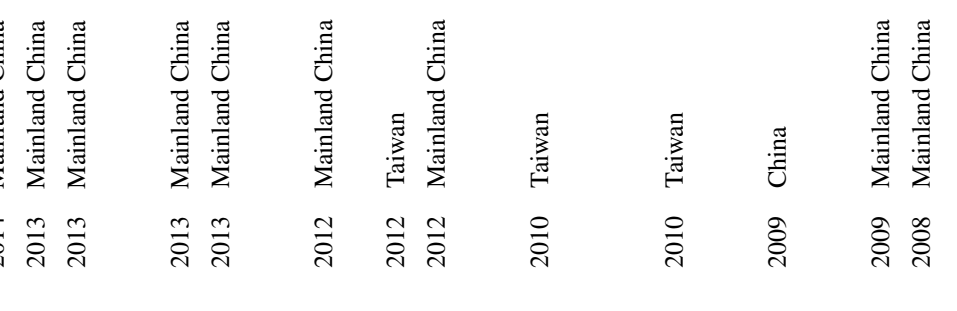




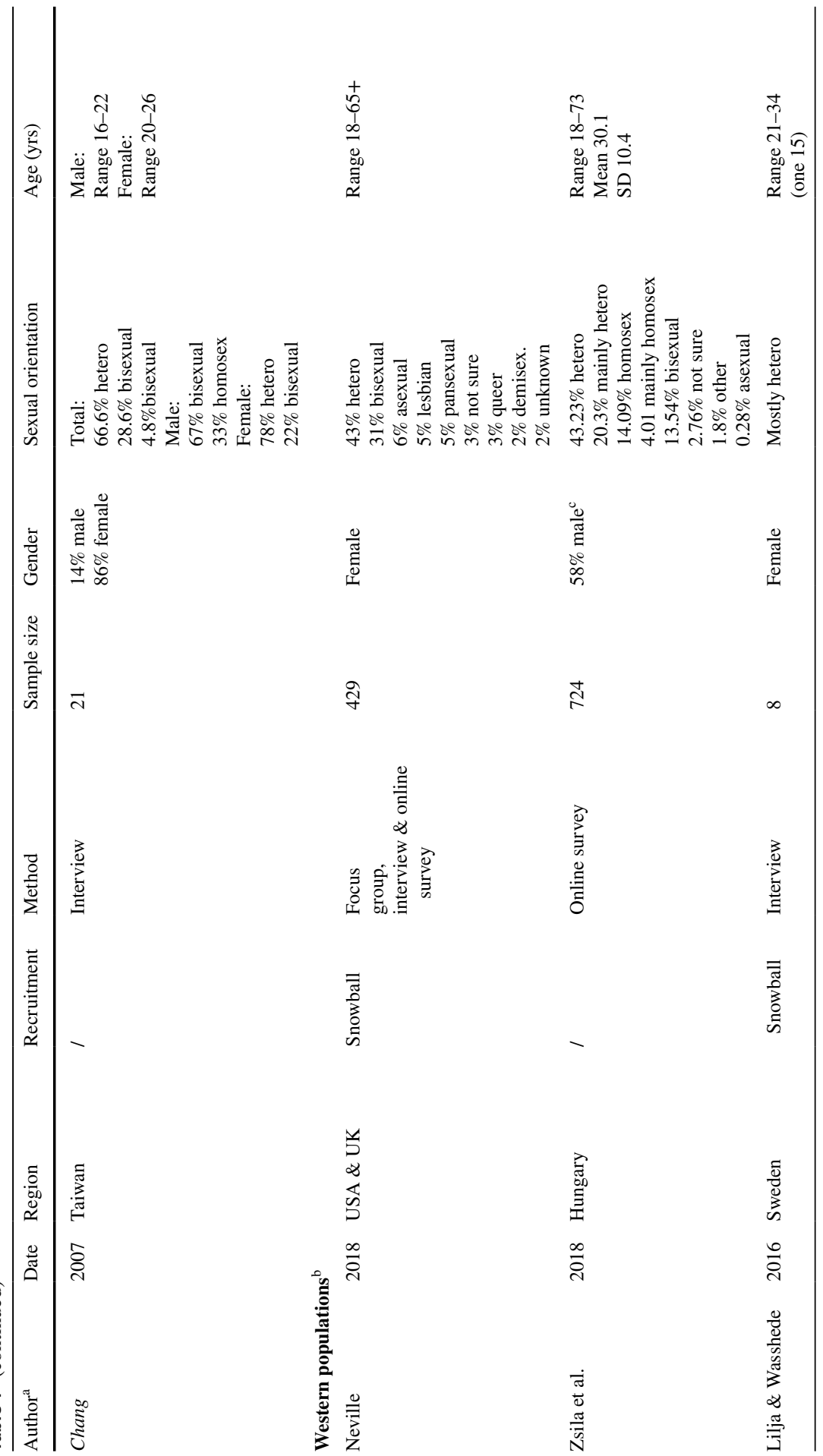




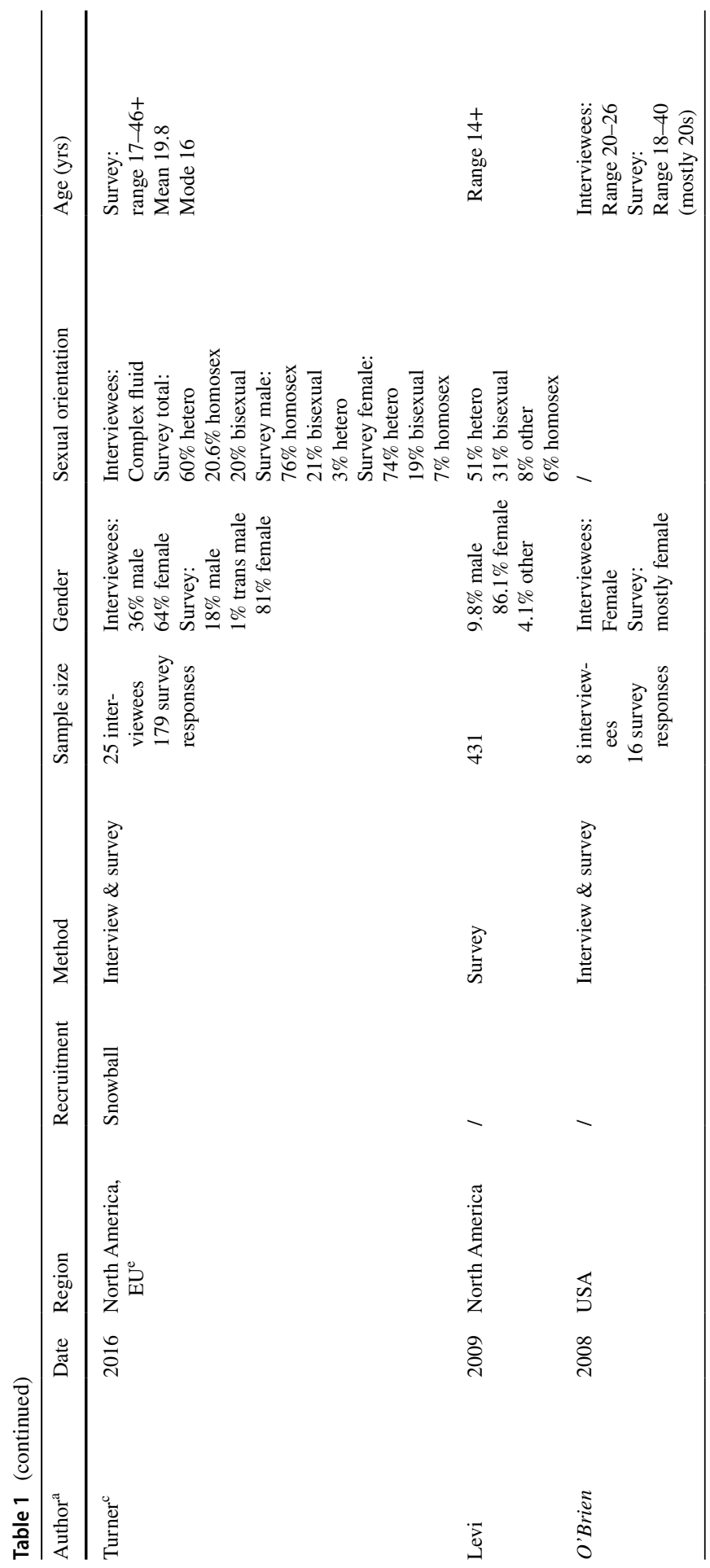




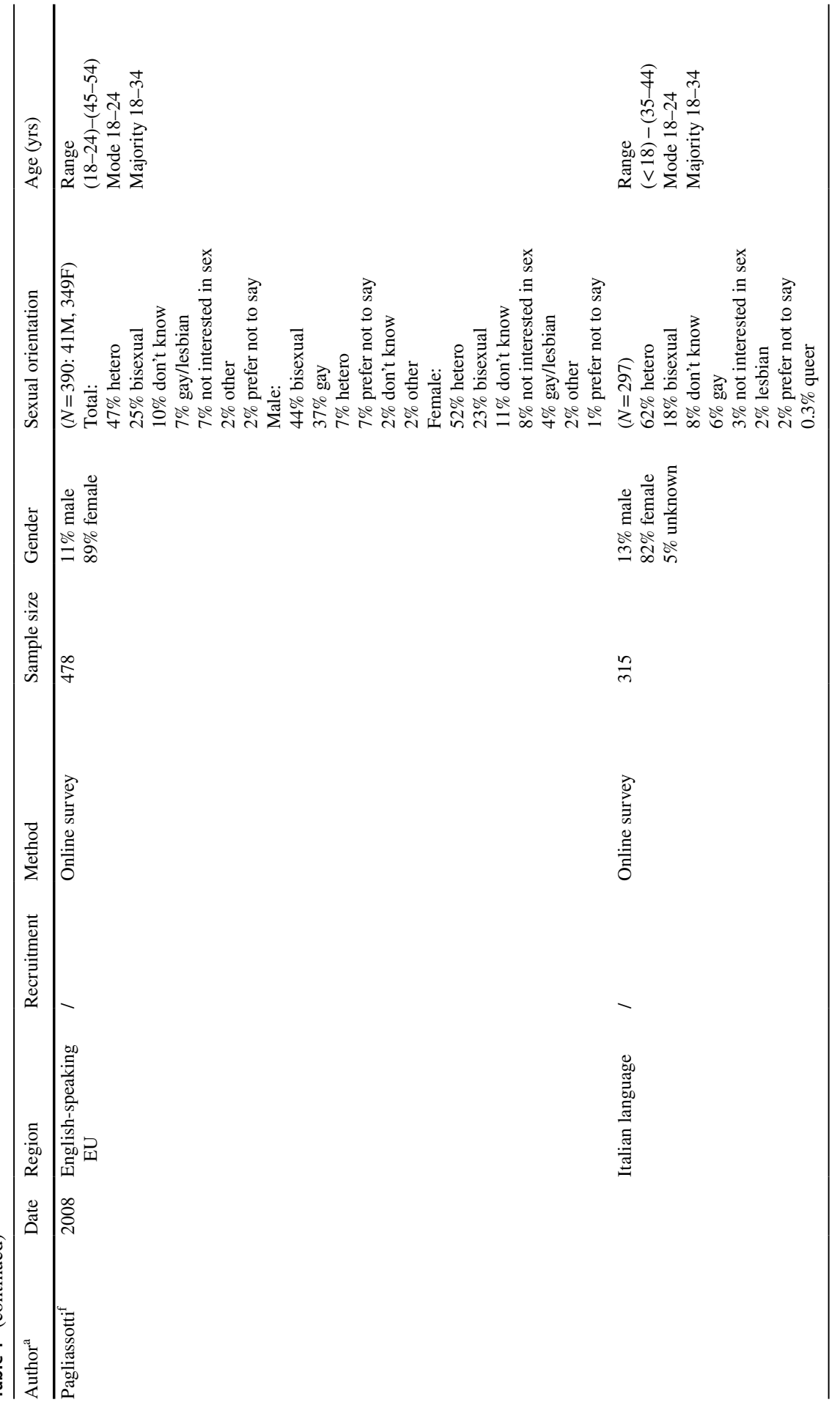




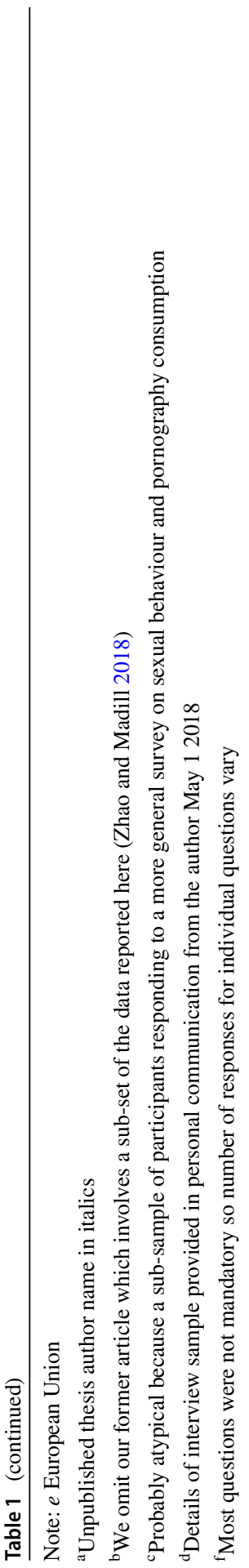


The research on BL which offers information on participant demographics first appeared in 2007-2008. We found 25 articles on the greater China area (of which 9 are unpublished student theses) and eight on the Anglophone West (of which one is an unpublished thesis).Chinese region research focuses on the audience in Mainland China ( $k=18$, including two conducted in 'China' which the authors at overseas' universities did not specify in more detail) and Taiwan $(k=7)$. Western population research includes countries in North America (USA, Canada) and Europe (UK, Hungary, Sweden, and Italy). However, it can be difficult to know who completes an online survey and the reporting of participant demographics is patchy. Sampling, when it is described, tends to be random or snowball, and data is collected via interviews and surveys.

Where interviews have been conducted with Chinese or Taiwanese participants, and their gender reported, all but one study interviewed only women (i.e., Chang 2007). Eight survey studies were identified in the greater China area articles (all in Mainland China) with sample size varying between 31 and 980. The larger surveys in the greater China area often target the general and student population, meaning that findings do not focus on BL fans. Where BL fans specifically have been surveyed, one included only women $(N=278$ : Hou and Xiao 2013) while the most recent is reasonably large and reveals a proportion (14\%) of male fans $(N=439$ : Yan 2018). Information on sexual orientation is not collected routinely and, when reported, heterosexual identification is high. The age range of participants is usually late teens through to late twenties.

As to Western population BL research providing demographic information, one is an interview study of women (Lilja and Wasshede 2016), four are surveys, and three are combined interview and survey studies. Pagliassotti (2008) reports two relatively large sample sizes for online surveys (English $N=478$; Italian $N=313$ ) which provide detailed demographic information. In contrast to the greater China area research, that on Western BL reports greater male engagement, wider range of sexual orientations, lower proportion of heterosexual identification, and a wider and older age range.

The general foci of these articles also provides an interesting context in which to consider difference in the engaged demographics. Mainland Chinese researchers sometimes demonstrate concern about the influence of BL on readers' sexual orientation. In particular, they have attempted to show that BL fans are at risk of rejecting heterosexuality through engaging with material that beautifies homosexuality (e.g., Liu and Tang 2012; Zhao 2016). In fact, one publication documents the process of 'rectifying' a female fan's sexual orientation through psychological counselling (Wu and Sun 2013). In contrast, the Taiwanese research, which has emphasized small group interview analysis, focuses much more on the positive aspects of BL culture such as its potential to help some women explore their sexual anxieties (Chang 2015). Similarly, the Western region research has tended to take a positive stance. For example, Turner (2016) outlines the potential for BL to promote a queer-friendly perspective in readers.

The relevant existing research on BL demonstrates that demographic data is sparse and often poorly reported. Hence, the aim of our research is to collect and compare comprehensive data with regard to the demographics engaged with malemale erotica in Anglophone regions and that of the greater China area. 


\section{Method}

\section{The Survey}

A 43-question online BL fandom survey was created from the existing literature and the authors' familiarity with the material: one version in English (https://leeds .onlinesurveys.ac.uk/blfandomsurvey) and an almost identical version in Simplified Chinese (https://www.wjx.cn/m/3989081.aspx). The Anglophone survey includes the question Is English your first language?, and provides option 'Polysexual/ Pansexual' in the question What is your sexual orientation?, while the Chinese survey includes the questions Are you a Chinese national?, In which Chinese province to you live? and If you do not live in Mainland China, in which country do you live? The survey consists of likert-scale and free-form response questions in five sections: demographics, BL materials, feelings about BL, social relationships, and other erotic materials. The survey in English is available for inspection as electronic supplementary material.

The Anglophone survey opened in November 2014 and was promoted via relevant internet forums, social network websites, and by e-mailing anime and manga clubs. The Chinese survey opened in March 2015 and was promoted via universities in Mainland China, leaflets distributed with products from an online Chinese BL shop, and at manga events in Mainland China at which a paper version of the survey was provided for immediate completion and transferred to the online version $(N=200)$. Data were collected until the end of January 2018. We also include data collected in one additional Chinese recruitment period during March 2018 and one additional Anglophone recruitment period during February and March 2019 to test an ensuing hypothesis with regard to potential recruitment bias.

The Chinese survey total $N=1498$ and the Anglophone survey total $N=1707$ (including only participants who noted their first language as English). Country of residence reported in the Chinese survey is: Mainland China 85.1\%; Hong Kong $13.2 \%$; UK $0.9 \%$. Nationality reported is: Chinese $97.7 \%$; Hong Kongese $2.2 \%$; Taiwanese $0.1 \%$. Hence, our sample has less Taiwanese as expected by regional population and none from Macau: Mainland China 1439 million, Taiwan, 23.8 million, Hong Kong 7.5 million, and Macau 0.6. This might have been influenced by the fact that our survey was in Simplified Chinese while Traditional Chinese is standard in Taiwan. Country of residence reported in the Anglophone survey is: USA $64.0 \%$; UK 19.5\%; Australia 5.6\%; Canada 4.9\%. Nationality reported is: American 44.4\%; British 19.5\%; Australian 4.2\%; Canadian 3.9\%. Hence, our sample is reasonably representative in terms of number of native English speakers in the more populated Anglophone countries: USA 231 million, UK 67 million, Australia 17.5 million, and Canada 5.7 million (Lyons 2017). 


\section{Creation of Two New Variables}

First, responses to What is your sexual orientation? were recoded to two categories 'Heterosexual' and 'Nonheterosexual,' the latter including responses Bisexual, Homosexual/lesbian/gay, Not sure, and Other (Chinese survey) and Bisexual, Homosexual/lesbian/gay, Polysexual/Pansexual, Not sure, and Other (Anglophone survey). This manages the fact that option 'Polysexual/Pansexual' was omitted from the Chinese survey given that it has little meaningful cultural relevance. Second, each participant response to At what age did you start to engage with BL? was subtracted from their response to What is your age in years? to create new variable Duration of Engagement.

\section{Survey Analysis}

The survey was designed in sections with a view to exploring several different research questions. In this article, twelve questions plus one created variable (Duration of Engagement) were analysed to explore possible difference in the engaged Anglophone and greater China area demographics. Hence, we selected for analysis all the questions in the demographics section of the survey, excluding two which we considered more relevant to a social values/ideology research question: i.e., items How acceptable are male-male sexual relationships to you in real life? and How acceptable are female-female sexual relationships to you in real life? We also selected for analysis two further items. The first, What percentage of your spare time do you spend on $B L$ ?, was selected as similar to the demographic section questions on BL-related activities (e.g., Do you create any BL works yourself?). The second, I discuss my interest in BL with friends I know in person (Never, Sometimes, Often, Very Often, Extensively) was selected because we were interested to compare the importance of anonymous engagement with BL between the two regions. The Chi Square test of independence was used to determine if two categorical variables are associated with one another for each observational unit. Because the likert scale response data are not normally distributed, the non-parametric test, the Mann-Whitney $\mathrm{U}$, is used to test for differences in median between and within groups. A demanding significance level of $p<.001$ was set and all analyses undertaken are reported regardless of significance level (see Tables $2 \& 3$ ). When significant, the size of the contrasts tested are reported, Cramer's $V$ (Chi square) and Pearson's $r$ (Mann-Whitney), where a small size $d=.1$, a medium size $d=.3$, and a large size $d=.5$ (Cohen 1988).

\section{Results}

The strongest differences (see Table 2) between the responses on the Chinese survey and the Anglophone survey are that those completing the Chinese survey were more likely: to be students; to be heterosexual; to have been 'Introduced to BL by others' as opposed to having 'Found BL by myself'; not to create BL works; and to 


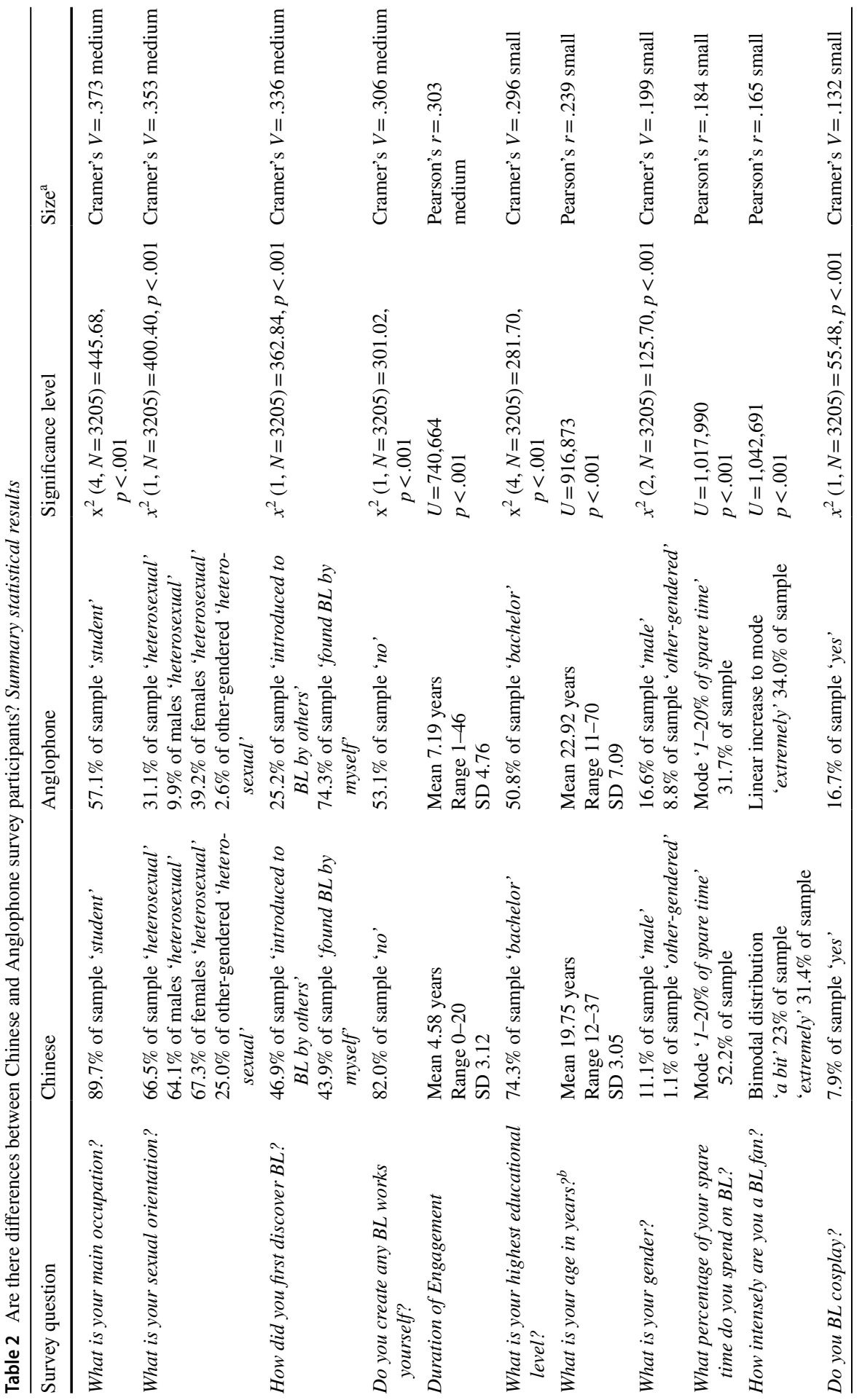




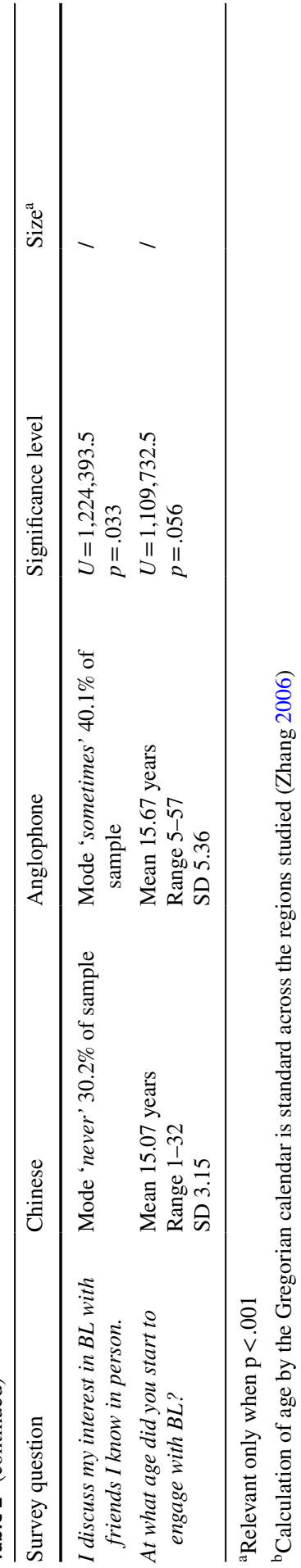




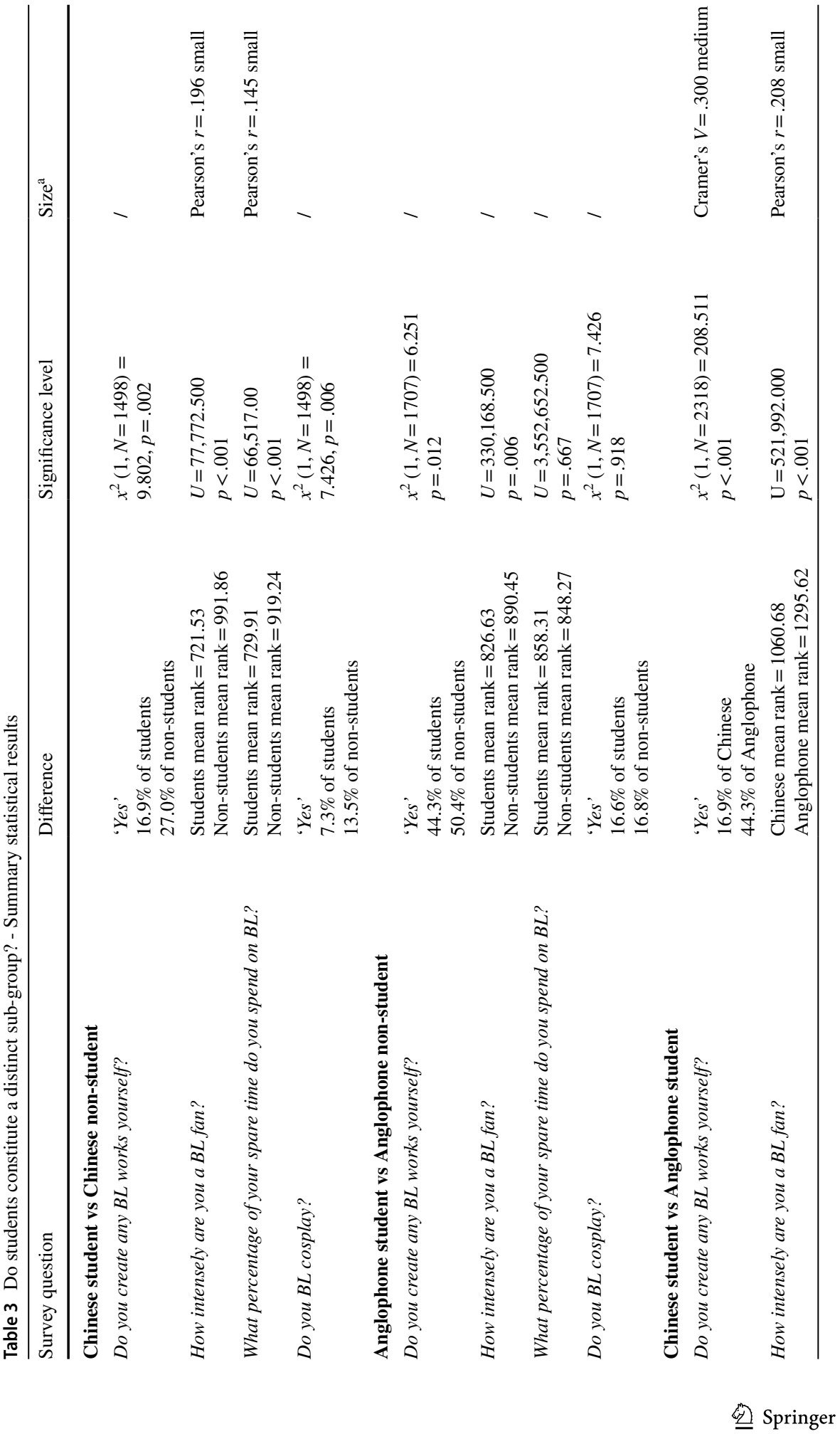




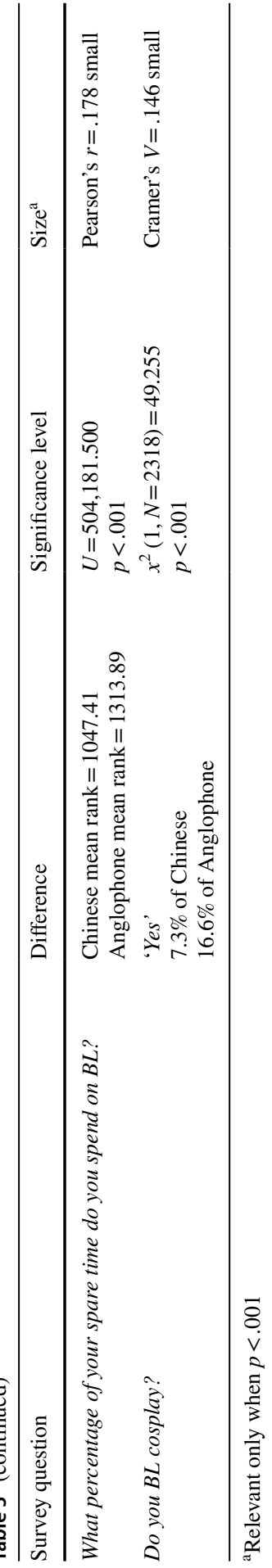


have a shorter duration of engagement. Other, less strong, differences are that those completing the Chinese survey were more likely: to report highest educational level, including current programme, as a bachelor degree; to be younger; to not be male or 'Other' gendered; to spend less of their spare time on BL; to be a less intense fan; and not to cosplay (i.e., 'costume play' whereby people dress-up as fictional characters). There were no differences between the responses on the Chinese survey and the Anglophone survey in the extent to which participants discuss their interest in BL with friends known in person and the age at which they started to engage with BL.

Of the Chinese survey participants who endorsed 'Other' gender, the freeform responses are: Hideyoshi (i.e., neither male nor female, and originates from the Japanese animation Baka and Test crossing-dressing male character; $N=4$ ), neutral $(N=3)$, hermaphrodite $(N=1)$, Futanair (i.e., both male and female; $N=1)$, no explanation $(N=7)$. Of the Anglophone participants who endorsed 'Other' gender, the free-form responses are: gender fluid $(N=28)$, gender queer $(N=27)$, agender $(N=26)$, trans $(N=24$; trans-male $=17$, trans-female $=5$, unknown $=2)$, non-binary $(N=18)$, bigender $(N=10)$, other one-off descriptions $(N=18)$.

The two participants in the Chinese survey who endorsed both 'Other' gender and 'Other' sexual orientation, indicated that they were 'asexual'. In total, of those who endorsed 'Other' sexual orientation in the Chinese survey, the freeform responses are: asexual $(N=6)$, pansexual $(N=5)$, "Single dog" $(N=1)$, no explanation $(N=6)$. Of the Anglophone participants who endorsed 'Other' sexual orientation, the free-form responses are: asexual $(N=128)$, demisexual $(N=26)$, grey $(N=7)$, queer $(N=4)$, other one-off descriptions $(N=21)$.

\section{Possible Bias in Chinese Survey Sample}

A possible bias in the Chinese sample is suggested by the comparatively large number of students compared to the Anglophone sample. Moreover, a possible impact of, and further evidence for a bias in the greater China area sample is the comparatively lower engagement in terms of creating BL works, BL cosplay, spare time spent on BL, and self-rated fan intensity. Hence, we posited the following three hypotheses: (a) greater Chinese area students constitute a distinct sub-group in terms of engagement in BL; (b) Anglophone students constitute a distinct sub-group in terms of engagement in BL; and (c) greater Chinese area students are less engaged in BL than are Anglophone students.

To test the first two hypotheses we conducted within sample comparisons of students versus non-students for both the greater China area and Anglophone survey data on the relevant four questions. To test the third hypothesis we conducted a between sample comparison of students in the greater China area and Anglophone survey data on the relevant four questions (see Table 3). The first hypothesis is partly upheld: that is, on two of the four questions Chinese survey student participants are less engaged in BL than are non-students: How intensely 
are you a BL fan? and What percentage of your spare time do you spend on BL? However, the trend on the other two questions is supportive of the hypothesis. The second hypothesis is not upheld: that is, on all four questions, there is no difference between Anglophone student and non-student participants. Finally, the third hypothesis is upheld: that is, on all four questions, greater Chinese area students are less engaged in BL than are Anglophone students. An important implication is that our Chinese survey student sample is distinctive in relation to the Anglophone student sample and may constitute a bias towards low engagement.

\section{Testing Potential Recruitment Bias}

The preponderance of students in our Chinese sample may reflect the way in which most Chinese survey recruitment was via university classes whereas almost all Anglophone survey recruitment was via the internet. This may have unduly affected findings because Chinese student participants are less engaged in BL than are Anglophone student participants and, in some ways, less engaged that are Chinese non-student participants. Hence, we tested for a potential recruitment bias through positing the following hypothesis: many more participants will be recruited via a Chinese university route than via an Anglophone university route.

To test this hypothesis, the Anglophone survey was promoted explicitly through Anglophone universities over about a 6 week period from the beginning of February 2019. Using our academic contacts we requested via e-mail that the Anglophone survey be distributed to students. One department at each of several different universities participated: UK $(N=6)$, Australia $(N=5)$, New Zealand $N=1)$, and USA $(N=1)$. No other recruitment activities were undertaken immediately before, during, or after this period. The ensuing Anglophone university participation pattern was contrasted with two example university recruitment periods in China, one during October 2017 and another during March 2018. In the first example period we had asked lecturers in one department to provide leaflets to students with a QR (quick response) code to the Chinese survey. In the second, an academic at a different university gave the link to his study group and asked them to distribute to other students. No other recruitment activities were undertaken immediately before, during, or after these two periods.

The recruitment period via Anglophone universities produced only a slight rise in survey completions. In contrast, the two example university recruitment periods in China produced a huge response with few participants in the prior months and the month following (see Table 4). Hence, the hypothesis is upheld: that is, many more participants were recruited via a Chinese university route than via an Anglophone university route. This provides evidence that our differential recruitment strategies were culturally appropriate and is unlikely to have biased the data. 
Table 4 Number of participants before, during, and after university recruitment periods in China (two example periods) and Anglophone countries (one period only)

\begin{tabular}{|c|c|c|c|c|c|}
\hline \multirow[b]{2}{*}{ Recruitment month } & \multicolumn{2}{|c|}{ Before } & \multicolumn{2}{|c|}{ During } & \multirow{2}{*}{$\begin{array}{l}\text { After } \\
5\end{array}$} \\
\hline & 1 & 2 & 3 & 4 & \\
\hline Chinese: university 1 & 0 & 0 & 603 & 34 & 1 \\
\hline Chinese: university 2 & 2 & 1 & 553 & 4 & 0 \\
\hline Anglophone: 13 universities & 5 & 1 & 5 & 8 & 1 \\
\hline
\end{tabular}

\section{Discussion}

The aim of our research is to collect and compare comprehensive data with regard to the demographics engaged with male-male erotica in Anglophone regions and that of the greater China area. Our study constitutes the largest such data set in each region and we have gathered wide-ranging information of interest. We confirm existing research which suggests that, in contrast to the greater China area, the engaged Anglophone demographic includes more men, people with a wider range of sexual orientations, lower proportion of heterosexual identification, and a wider and older age range, alongside additional new information and detail.

In particular, we provide novel evidence that a broad demographic of young people in the greater China area is familiar with BL as a casual interest in contrast to Anglophone regions where it is more of an intense and niche pass-time. Specifically, while Anglophone participants do not differ in their engagement in $\mathrm{BL}$ according to student status, there is a preponderance of students in our Chinese sample who are also less engaged in BL than are Anglophone students and, in some ways, less engaged that are the Chinese non-students. Importantly, we provide evidence these findings are unlikely to be an artefact of recruitment bias and that we have revealed a, possibly surprising, real difference in the way in which BL culture operates in the greater China area and the Anglophone West.

Chinese culture emphasizes cohesiveness and prioritization of group over self (Oyserman 1993). In contrast, Anglophone culture tends to encourage individualism (Veenhoven 1999). This might help explain the comparatively wider, but lower-level, engagement with BL in the greater China area and is supported by our finding that, whilst both populations were reticent to discuss BL with friends they know in person, those who completed the Chinese survey were more likely to have been introduced to BL by others. That is, BL may be diffused more widely in the greater China area because young people feel safer and more accepted if their interest in $\mathrm{BL}$ is shared with others and can promote it online with relative anonymity. Casual engagement in BL may also be influenced by the fact that middle/high school and university students in the greater China area have limited free time compared to those in many Anglophone countries (Hays 2012), including free time to read and watch BL, create original work, or undertake preparations for cosplay. In relation to the latter, many high schools in the greater China area do not allow students to use make-up and most universities do not encourage it (Hays 2012). Hence, since cosplay can require skill with make-up, many young people in the greater China area may feel disinclined to take part. 
The shorter history of BL in the greater China area could help account for the younger mean age of those completing the Chinese survey and their shorter duration of engagement compared to the Anglophone. BL culture took-off in the Anglophone West during the 1980s (Madill 2018), but did not gain traction in the greater China area until the late 1990s (Wei 2014). Interestingly, our results reveal no difference in the age of first engagement with BL (15 years old in both regions), which is in line with the available existing research (Pagliassotti 2008). Chinese fans and researchers sometimes express concern that people are engaging with BL at an increasingly young age (e.g., Zhang 2015). Our Chinese survey data, which was collected between 2015 and 2018, may, indeed, indicate a slightly lower mean age than earlier reports. This may be linked to improved internet access and it is likely that interest in erotica is influenced by psychosexual development in which culture plays only a small part when materials are readily available. Erikson suggests that development from infancy to adulthood occurs in eight stages (Stevens 1983). Between 13 and 19 years is the stage called 'Identity Confusion' in which teenagers attempt to establish a stable sense of self, including a sexual identity (Kail and Cavanaugh 2004). Hence, some teenagers may start to engage with BL as a way of exploring different kinds of romantic and sexual relationships and identities. Although our Anglophone sample was older than that of the greater China area, the mean was influenced by a long 'tail' of older participants and Turner's (2016) survey of North American and European Union BL fans reports a very similar mean age to that of our Chinese survey sample. Again suggesting a possible life-stage phenomenon, mean age is within the peak age range for engagement with pornography (i.e., 18-25 years), particularly by women, reported by Attwood et al. (2019).

Our greater China area sample is more heterosexual, less male, and less likely to identify as 'Other' gendered than the Anglophone. Even so, our study reports a lower proportion of heterosexuality in the greater China area BL fandom (i.e., $65.5 \%$ ) compared to recent research such as Yan (2018) who reports $80 \%$ heterosexuality. A possible explanation is that our option 'Not sure' provided our participants an easy, alternative default to identifying as heterosexual. Substantiating this, $80 \%$ of our Chinese sample endorsed 'Not sure' or 'Heterosexual'. Our survey, therefore, usefully disentangles participants who are positively heterosexual from those who are still questioning. This may be particularly important for a largely youth demographic, and one actively engaged in queer material.

Mainstream culture in the greater China area highlights traditional family values, filial piety, and patriotism, and authorities and official media emphasize and promote the family as the essential unit of social stability ( $\mathrm{Mu} 2012$ ). Hence, young people are expected to conform to normative gender roles and the heterosexuality implied. Leta et al. (2015) document how single Chinese women in their middle to late $20 \mathrm{~s}$ experience social and familial pressure to marry and risk being denigrated as 'leftover women.' Hence, Chinese women involved in BL culture might be overly inclined to identify as heterosexual given public concern that BL could alienate them from taking-up the role of wife and mother (e.g., Liu and Tang 2012; Zhao 2016).

Men in the greater China area may be unwilling to engage with BL material because it is perceived as a female interest and might imply that they are not 
heterosexual. Indeed, in our sample, only $11.1 \%$ of participants who completed the Chinese survey were male compared to $16.6 \%$ who completed the Anglophone. There is little or no research providing good comparative data for the sexual identity of male BL fans in the greater China area. However, $64.1 \%$ of male participants who completed our Chinese survey endorsed 'Heterosexual', compared to only $9.9 \%$ of our male Anglophone participants, the latter which is even a little higher that previous surveys of Western BL fans: 3\% (Turner 2016) and 7\% (Pagliassotti 2008). The comparative figures suggest that male nonheterosexuality may be under-reported in our Chinese survey. However, heterosexual male BL fans are an interesting demographic and our study confirms that a proportion of young straight-identifying men in both the Anglophone West and greater China area are engaging actively in malemale erotica.

Only $39.2 \%$ of our female Anglophone participants identified as heterosexual. This is relatively low compared to existing research on the Western BL fandom. Our study might suggest that young Anglophone women, particularly those interested in an erotic subculture like BL, are increasingly questioning of heteronormativity. Morgan and Thompson (2011) evidence a similar conclusion in relation to American college students. There is a similar picture with regard to gender, with more Anglophone than greater China area participants identifying as 'Other' gendered, and with a wide range of specific descriptions. Interestingly, although translation is a complicating factor and Chinese participants were, in general, less likely to provide free-form responses, they sometimes drew creatively on popular culture terms and characters to describe alternative gender and sexual identities. Hence, queer popular culture may be offering young people a means for extending their identity lexicon for otherwise ineffable experiences.

In conclusion, our study provides the most extensive and comprehensive data with regard to the demographics engaged with male-male erotica in Anglophone regions and that of the greater China area. We confirm that the engaged Anglophone demographic includes more men, people with a wider range of sexual orientations, lower proportion of heterosexual identification, and a wider and older age range. We provide additional detail and information on engagement with BL by young straight men and questioning of sexual identity by female fans, at least in the Anglophone West. We also provide novel evidence that a broad demographic of young people in the greater China area is familiar with BL as a casual interest in contrast to Anglophone regions where it is more of an intense and niche pass-time.

\section{Compliance with Ethical standards}

Conflict of interest No potential conflict of interest was reported by the authors.

Availability of Data and Material The survey in English is available as electronic supplementary material. We are still publishing from our data so wish to keep it private.

Ethics Approval Approval was obtained from the Ethics Committee of the School of Psychology University of Leeds, UK. The procedures used in this study adhere to the tenets of the Declaration of Helsinki. 
Open Access This article is licensed under a Creative Commons Attribution 4.0 International License, which permits use, sharing, adaptation, distribution and reproduction in any medium or format, as long as you give appropriate credit to the original author(s) and the source, provide a link to the Creative Commons licence, and indicate if changes were made. The images or other third party material in this article are included in the article's Creative Commons licence, unless indicated otherwise in a credit line to the material. If material is not included in the article's Creative Commons licence and your intended use is not permitted by statutory regulation or exceeds the permitted use, you will need to obtain permission directly from the copyright holder. To view a copy of this licence, visit http://creativecommons.org/licen ses/by/4.0/.

\section{References}

Attwood, F., Smith, C., \& Barker, M. (2019). Engaging with pornography: An examination of women aged 18-26 as porn consumers. Feminist Media Studies. https://doi.org/10.1080/14680 777.2019.1681490.

Chang, Y. (2007). Crucifix entwisted with roses: Culture study on BL audience [Unpublished Masters thesis] National Taiwan University.

Chang, C. (2015). Positive emotions generated from pleasure reading: Exploring the perception of 'healing' for female Boys' Love readers in Taiwan [Unpublished Masters thesis] National Taiwan University.

Cohen, J. (1988). Statistical power analysis for the behavioral sciences (2nd ed.). New Jersey: Lawrence Erlbaum.

Hays, J. (2012). School life in China: Rules, report cards, files, classes and teachers, Facts and details. http://factsanddetails.com/china/cat13/sub82/item1094.html.

Hou Q., \& Xiao K. (2013). The study of the 'yaoi fandom' gender role and the self-consistency and congruence. Journal of Shaoguan University Social Science 侯秋霞 萧凯欣 “腐女”性别角色及自我和 谐状态㸴究《韶关学院学报社会科学》。

Kail, R. V., \& Cavanaugh, J. C. (2004). Human development: A life-span view (3rd ed.). Belmont: Thomson/Wadsworth.

Leta, H. F., Hong, L., \& Chen, X. (2015). Chinese leftover women. Taipei: Baqiwenhua.

Levi, A., McHarry, M., \& Pagliassotti, D. (Eds.). (2014). Boys' Love Manga: Essays on the sexual ambiguity and cross-cultural fandom of the genre. Jefferson: McFarland.

Lilja, M., \& Wasshede, C. (2016). The performative force of cultural products: Subject positions and desires emerging from engagement with the manga, Boys' Love and Yaoi. Culture Unbound: Journal of Current Cultural Research, 8(3), 284-305.

Liu, D., \& Tang, K. (2012). Analysis of fujoshi group's virtual life behaviours. Journal of Mudanjiang University, 21(11). 刘东 唐鬼玉 “同人女”群体中的虚拟生活行为析论《牡丹江大学学报》.

Lyons, D. (2017). How many people speak English, and where is it spoken? Babbel Magazine. https:// www.babbel.com/en/magazine/how-many-people-speak-english-and-where-is-it-spoken.

Madill, A. (2015). Boys' Love manga for girls: Paedophilic, satirical, queer readings and English law. In E. Reynold, J. Ringrose, \& R. D. Egan (Eds.), Children, Sexuality and Sexualisation (pp. 273-288). London: Palgrave Macmillan.

Madill, A. (2018). Erotic manga: Boys' Love, Shonen-Ai, Yaoi and (MxM) Shotacon. In C. Smith, F. Attwood, \& B. McNair (Eds.), Routledge companion to media, sex and sexuality (pp. 130-140). Abingdon: Routledge.

Morgan, E. M., \& Thompson, E. M. (2011). Processes of sexual orientation questioning among heterosexual women. Journal of Sex Research, 48(1), 16-28.

$\mathrm{Mu}$, Q. (2012). Discussion of the modern Chinese family: Comparison of Chinese and Western moral ideology between the individual and the family. Social Sciences Journal of Shanxi University, 8 慕 旗娟 2012 浅论当代中国家庭伦理的构建一基于中西方个人与家庭伦理观的对比, 山西高校学 校社会科学学报 第八期.

Oyserman, D. (1993). The lens of personhood: Viewing the self, others, and conflict in a multicultural society. Journal of Personality and Social Psychology, 65, 993-1009.

Pagliassotti, D. (2008). Reading Boys' Love in the West. Participations 5(2). http://www.participations. org/Volume 5/Issue 2/5_02_pagliassotti.htm. 
Porter, L. (Ed.). (2012). Sherlock Holmes for the 21st century: Essays on the new adaptations. Jefferson: McFarland.

Stevens, R. (1983). Erik Erikson: An introduction. New York: St. Martin's.

Turner, S. D. (2016). Making friends the Japanese way: Exploring yaoi manga fan's online practices. Mutual Images [Online], Vol. 1, Summer, 47.

Veenhoven, R. (1999). Quality-of-life in individualistic society. Social Indicators Research, 48(2), $159-188$.

Wei, J. (2014). Queer encounters between Iron Man and Chinese boys' love fandom. Transformative Works and Cultures, 17. https://papers.ssrn.com/sol3/papers.cfm?abstract_id=2649256.

Wu, W., \& Sun, L. (2013). The influence of tanbi materials on the sexual psychology of high school female student. Primary and Middle School Mental Health Education. 吴伟强 孙黎黎耽美作品对 高中女生性心理的影响研究《中小学生心理健康教育》.

Yan, W. (2018). Current status of Chinese tanbi novels. Journal of North China University of Water Resources and Hydropower (Social Science Edition), 134-137.

Zhang, Q. (2006). Thoughts on adoption of Gregorian calendar in China. Journal of Xidian University (Social Science Edition). http://en.cnki.com.cn/Article_en/CJFDTotal-XADZ200606019.htm.

Zhang, Y. (2015). An exploratory study of the influence of BL culture on fujoshi's sexual orientation. Young Writers. 张露月 腐文化对腐女性取向影响的实证㸴究《青年作家》.

Zhang, C. (2016). Loving boys twice as much: Chinese women's paradoxical fandom of 'Boys' Love' fiction. Women's Studies in Communication, 39, 249-267.

Zhao, K. (2016). The influence of online tanbi novels to university students' ideas of homosexuality. Literature Education. 赵柯,网络耽美文学对大学生同性恋观念的影响, 文学教育.

Zhao, Yao, \& Madill, A. (2018). The heteronormative frame in Chinese yaoi: Integrating Chinese fan interviews with Sinophone and Anglophone survey data. Journal of Graphic Novels \& Comics, $9(5), 435-457$.

Publisher's Note Springer Nature remains neutral with regard to jurisdictional claims in published maps and institutional affiliations. 